\title{
Analisis Faktor Penyebab Siswa Lambat dan Cepat Belajar Kelas IV di SDN Kp. Bulak III Pamulang
}

\author{
Septy Nurfadhillah ${ }^{1 \bowtie}$, Adinda Rahmah Ishaq ${ }^{2}$, Miftah Nurul Annisa ${ }^{3}$, \\ Gestiana Ragin ${ }^{4}$, Rifdah Fauziah ${ }^{5}$, Ade Williah ${ }^{6}$, Wulan Novianty ${ }^{7}$ \& Aldi \\ Sutisna ${ }^{8}$
}

Prodi PGSD, Universitas Muhammadiyah Tangerang, Indonesia

$\bowtie$ E-mail: Nurfadhillahsepty@gmail.com

\begin{abstract}
Abstrak
Tujuan dari penelitian ini ialah untuk mengetahui mekanisme penerimaan siswa, pembelajaran, dan penanganan pada siswa lambat dan cepat belajar kelas IV di SDN Kp. Bulak III Pamulang. Penelitian ini menggunakan metode penelitian deskriptif kualitatif dengan jenis penelitian studi kasus serta subjek penelitian 2 orang siswa kelas IV dan 1 guru kelas IV. Instrument penelitian yang digunakan ialah observasi, wawancara, dokumentasi, dan catatan lapangan. Teknik analisis data dilakukan sesuai dengan prosedur ilmiah penelitian kualitatif studi kasus. Mekanisme penerimaan siswa yaitu system penerimaannya sama seperti anak lain. Cukup umur, sehat. Misal ada ketebelakangan tetapi masih bisa merespon, bisa diajak berkomunikasi, siswa tersebut masih diterima. Pembelajaran yang dilakukan hampir seluruhnya sama seperti umum, hanya saja yang membedakan ialah pendekatan yang guru lakukan kepada siswa lamban belajar yang lebih diprioritaskan. Sedangkan untuk siswa cepat belajar, guru sering meminta siswa untuk membantu temannya menjelaskan materi yang belum dipahami. Penanganan yang dilakukan guru kepada siswa ialah melakukan pendekatan persuasif atau kasih sayang, mengatur posisi duduk, menjadikan siswa prioritas dalam belajar, serta mengajak siswa aktif dalam membantu temannya belajar.
\end{abstract}

Kata Kunci: Pendidikan Inklusif; Lambat Belajar; Cepat Belajar

\begin{abstract}
The purpose of this study is to find out the mechanisms of student admission, learning, and handling in students slow and fast learning grade IV in SDN Kp. Bulak III Pamulang. This research uses qualitative descriptive research methods with this type of case study research as well as the research subjects of 2 grade IV students and 1 grade IV teacher. The research instruments used are observations, interviews, documentation, and field records. Data analysis techniques are carried out in accordance with the scientific procedures of qualitative research of case studies. The mechanism of admission of students is the same admission system as other children. Old enough, healthy. For example, there is backwardness but can still respond, can be invited to communicate, the student is still accepted. Learning that is done almost entirely the same as general, only what distinguishes is the approach that teachers do to students slow learning that is prioritized. As for students quickly learning, teachers often ask students to help their friends explain material that is not yet understood. The handling of the teacher to students is to take a persuasive or affectionate approach, set a sitting position, make students a priority in learning, and invite students to be active in helping their friends learn.
\end{abstract}

Keywords: Inclusive Education; Slow Learner; Fast Learner 


\section{PENDAHULUAN}

Pendidikan menurut Undang-undang Republik Indonesia nomor 20 Tahun 2003 tentang Sistem Pendidikan Nasional pasal 1 menyatakan: "Pendidikan adalah usaha sadar dan terencana untuk mewujudkan suasana belajar dan proses pembelajaran agar peserta didik secara aktif mengembangkan potensi dirinya untuk memiliki kekuatan spiritual keagamaan, pengendalian diri, kepribadian, kecerdasan, akhlak mulia, serta keterampilan yang diperlukan dirinya, masyarakat bangsa dan negara. (Kemendikbud, 2003)

Pendidikan adalah Proses social yang terjadi pada orang yang dihdapkan pada pengaruh lingkungan terpilih dan terkontrol (khususnya yang datang dari sekolah) sehingga memperoleh pengembangan kemampuan sosial dan kemampuan individu yang optimum.

Peraturan Menteri Pendidikan Nasional Republik Indonesia No. 70 Tahun 2009 tentang Pendidikan Inklusif Bagi Peserta Didik yang Memiliki Kelainan dan Memiliki Potensi Kecerdasan dan/atau Bakat Istimewa, siswa yang termasuk anak berkebutuhan khusus meliputi: 1) anak tunanetra; 2) anak tunarungu; 3) anak tunawicara; 4) anak tunagrahita; 5) anak tunadaksa; 6) anak tunalaras; 7) anak berkesulitan belajar; 8) anak lamban belajar (slow learners); 9) anak autis; 10) anak yang memiliki gangguan motorik; 11) anak yang menjadi korban penyalahgunaan narkoba, obat terlarang, dan zat adiktif lainnya; 12) anak yang memiliki kelainan lainnya; dan 13) anak tunaganda. (UNIMUS, 2012)

Anak lamban belajar atau slow learners adalah salah satu anak berkebutuhan khusus yang membutuhkan layanan pendidikan khusus di sekolah inklusi yang memiliki prestasi belajar rendah atau sedikit dibawah rata - rata pada anak normal. Layanan pendidikan khusus tersebut dibutuhkan karena anak lamban belajar harus menghadapi beberapa masalah belajar, seperti: 1) kesulitan memahami konsep abstrak; 2) mempunyai kosa kata yang terbatas; 3) mempunyai motivasi belajar yang rendah; 4) membutuhkan waktu yang lebih lama untuk memahami suatu materi dibandingkan anak normal seusianya; dan 5) membutuhkan pengulangan dalam penjelasan materi.

Berdasarkan observasi yang dilakukan di SDN Kampung Bulak 3 Tangerang Selatan, sekolah tersebut terdapat siswa yang memiliki lamban belajar dan cepat belajar. Kondisi ini yang nantinya akan penulis kaji untuk mengetahui mengenai kurikulum, mekanisme, serta evaluasi yang diselenggarakan di sekolah tersebut untuk menangani siswa yang berkebutuhan khusus. Selain itu, penulis juga akan mencari faktor apa saja yang menyebabkan siswa lamban dan cepat dalam belajar. Hal ini akan mempengaruhi kinerja guru di sekolah, bagaimana guru tersebut menangani dan mengatasi kendala belajar yang ada dengan adanya siswa dengan kondisi lamban dan cepat dalam belajar.

\section{METODE PENELITIAN}

Penelitian ini dilakukan pada semester ganjil tahun akademik 2021/2022. Subjek penelitian ini adalah guru dan siswa kelas IV SD wilayah Tangerang Selatan. Penelitian ini termasuk kedalam penelitian kualitatif dengan pendekatan deskriptif dengan jenis penelitian studi kasus yang didalamnya memuat wawancara terhadap peserta didik serta guru kelas IV SDN Kp. Bulak III Pamulang

Tujuan dari penelitian ini ialah untuk mengetahui mekanisme penerimaan siswa, pembelajaran, dan penanganan pada siswa 
lambat dan cepat belajar kelas IV di SDN Kp. Bulak III Pamulang. Penelitian ini diadakan melalui observasi, wawancara, dokumentasi, dan catatan lapangan.

Penelitian ini dilaksanakan pada bulan November 2021. Subjek dalam penelitian ini adalah guru serta siswa kelas IV SD.

\section{HASIL DAN PEMBAHASAN}

\section{A. Jenis Ketunaan}

\section{Anak Lamban Belajar: MS}

Anak MS memiliki jenis ketunaan anak lamban belajar. Anak lamban belajar dikenal dengan istilah slow learners, backward, dull, atau borderline. Mumpuniarti (2007: 14) mengidentifikasi anak lamban belajar sebagai anak yang mempunyai IQ di antara 70 sampai 89.

\section{Anak Cepat Belajar: MF}

Anak MF memiliki jenis ketunaan cepat belajar (Fast Learner). Fast Learner adalah anak yang berbakat dalam hal intelektual, dimana selain memiliki kemampuan intelektual diatas rata-rata normal yang signifikan juga memiliki kreatifitas dan tanggung jawab terhadap tugas. Karakteristik anak yang termasuk dalam kategori ini mampu belajar dengan cepat.

\section{B. Kelebihan dan Kelemahan Anak}

Anak MS:Kelebihan: Tidak membalas ejekan teman, menerima kekurangan nya dalam pembelajarannya, tidak minder. Kekurangan: Suka belajar menyendiri, kurang suka diskusi, terlalu introvert, respon saat diajak berbicara cukup lama, bisa tidak merespon jika berbicara dengan orang baru atau tidak dikenal.

Anak MF: Kelebihan: Cepat merespon pembelajaran disbanding teman sebayanya. Selalu melakukan pembelajaran dimalam hari untuk pembelajaran hari esoknya. Kekurangan: Dalam berbicara agak sedikit gagap.

\section{Penyesuaian Pembelajaran yang digunakan ABK}

Anak MS: Hampir seluruhnya sama dalam kegiatan pembelajaran, untuk anak yang memiliki keterbelakangan dalam pembelajaran, biasanya guru melakukan pendekatan yang khusus terhadap siswanya. Guru menjadikan siswa tersebut sebagai prioritas dalam belajar agar bisa mengikuti pelajaran seperti teman-teman yang lain.

Anak MF: Hampir seluruhnya sama dalam kegiatan pembelajaran, untuk anak yang memiliki keterbelakangan dalam pembelajaran, biasanya guru melakukan pendekatan yang khusus terhadap siswanya. Siswa dengan cepat belajar bukan berarti tidak mendapat perhatian dari guru. Siswa tetap mendapat perhatian dan kasih sayang dari guru. Terkadang guru meminta tolong untuk membantu temannya menjelaskan materi yang belum dipahami.

\section{Kurikulum dan Evaluasi Pendidikan Inklusi Yang Berlaku \\ Di sekolah SDN Kampung Bulak 3}

Secara keseluruhan tidak ada kurikulum khusus untuk pendidikan inklusi. Masih pakai kurikulum yg dianjurkan dari pemerintah yaitu Kurikulum 2013 dan SD ini juga tidak mengembangkan kurikulum Pendidikan inklusi yang ada. Di SD ini belum mengembangkan kurikulum sesuai dengan macam-macam model pengembangan kurikulum karena sekolah tidak bisa membedakan antara anak berkebutuhan khusus (abk) dengan non-abk. Kurikulum 2013 adalah suatu kebijakan pemerintah pada bidang pendidikan untuk menjawab tantangan dan persoalan yang akan dihadapi bangsa Indonesia. Kurikulum 2013 menekankan pada proses pendidikan yang holisotik sehingga menyentuh pada cakupan yang lebih luas pada ranah kognitif, afektif 
dan psikomotorik. Di sekolah ini juga menyamaratakan bahwa semua murid ini sama.

Sekolah ini juga belum ada rencana untuk mengembangkan kurikulum yg ada untuk menyesuaikan dengan siswa abk disekolahnya, tetapi dari sekolah jikalau dianjurkan atau mengharuskan kurikulum inklusi atau menggunakan pengembangan kurikulum atas perintah pemkot atau pemda, sekolah ini siap melaksanakan. Tapi kalau masih simpang siur, atau belum jelas info wajib atau tidaknya, maka sekolah ini tidak menerapkan kurikulum tersebut. Bentuk evaluasi yang dilakukan sekolah ini disama ratakan antara siswa abk dan non-abk, dengan soal yang sama. Tiap kenaikan kelas ada rapat khusus untuk mengidentifikasi siswa yang kurang atau keterbelakangan. Misal ada hal semacam itu, guru melakukan musyawarah apakah anak tersebut layak untuk naik kelas atau tidak. Karena ada beberapa kasus siswa tidak bisa membaca sampai kelas 4, tetap dinaikkan sampai sekarang kelas 6. Hal tersebut bisa menjadi bahan evaluasi apakah siswa tersebut harus lulus atau tetap tinggal. Tetapi untuk saat ini, belum ada kasus yang parah sampai siswa harus dipindahkan ke sekolah lain.

\section{E. Mekanisme Pelaksanaan Pendidikan Inklusi}

Mekanisme penyelenggaraan pendidikan inklusi di SDN Kampung Bulak 3 sama seperti pendidikan pada umumnya. Karena sekolah ini bukan sekolah khusus atau fokus seperti pendidikan sekolah inklusi. Namun, masih menerima siswa dengan latar belakang kebutuhan khusus namun dengan syarat tertentu. Pelaksanaan di kelas, guru tetap melakukan pendekatan persuasive pada anak-anak yang dirasa membutuhkan pendekatan tersebut. Guru kelas 4 di SDN Kampung Bulak 03 mengatakan tidak ada kendala selama mengatasi pelaksanaan pembelajaran tersebut. System penerimaan abk di sekolah ini sebagai contohnya ketika penerimaan siswa baru, system penerimaannya sama seperti anak lain. Cukup umur, sehat. Misal ada ketebelakangan tetapi masih bisa merespon, bisa diajak berkomunikasi, siswa tersebut masih diterima. Karena anjuran aturan pemerintah, anak tidak bisa membaca atau menulis, tetap harus diterima. Selain itu dilakukan tes mengenal huruf atau angka. Jika anak tidak bisa pun tetap harus diluluskan. Tujuan tes tersebut dilakukan untuk menandai anak tersebut bisa membaca atau tidak agar guru nantinya memiliki langkah atau strategi yang bisa terapkan kepada siswa tersebut.

cenderung memiliki karakter yang sama jadi, sulit untuk membedakannya.

\section{F. Penanganan Guru}

Cara guru menangani siswa dengan lamban belajar ialah: Penanganan yang guru lakukan ialah mengambil tindakan bentuk awal melalui pendekatan persuasive atau penuh kasih sayang. Ada pelakukan khusus dibanding siswa yang lain. Sebagai contoh: posisi duduk. Posisi tempat duduk siswa lamban belajar ada di depan bukan di belakang. Hal ini bertujuan agar guru bisa mengkontrol siswa-siswa tersebut dengan mudah. Dengan kata lain, siswa lamban belajar menjadi prioritas dalam pembelajaran di kelas.

Cara guru menangani siswa dengan cepat belajar ialah: Perlakuannya sama seperti anak murid pada umumnya. Tidak ada perlakuan khusus seperti siswa lamban belajar.

\section{G. Indicator}

Indicator yg menjadi acuan anak dikategorikan lamban belajar dan yg menjadi acuan anak dikategorikan lamban belajar dan 
cepat belajar yaitu dilihat dari proses belajar di kelas dan hasil belajar yang ditunjukan di akhir pembelajaran maupun akhir semester. Selain itu juga sikap yang ditampilkan di kelas. Anak yang hyperaktif atau bahkan tidak bersosialisasi, berteman, atau berbicara dengan temannya juga menjadi indicator bahwa anak tersebut memiliki gangguan terhadap belajar salah satunya lamban belajar.

\section{H. Kendala Bagi Guru dan Siswa Dalam Pembelajaran Di Kelas}

Apakah ada kendala bagi siswa maupun guru dalam pembelajaran di kelas? Diantaranya; a) Untuk kasus lamban belajar: jika terlalu banyak anak yang mengalami hal tersebut, guru kesulitan untuk mengatur keadaan kelas dalam belajar, b) Masih terdapat kasus bullying atau dikucilkan oleh teman sebaya. Kasus bullying banyak ditemukan di kelas 3 dan 4, c) Kendala dari wali muridnya yaitu, banyak orang tua yang tidak terima jika anaknya dikategorikan sebagai lamban belajar, d) Wali murid dari anak yang cepat belajar juga ada yang tidak mau anaknya berteman dengan anak yang lamban belajar.

\section{Guru Menghadapi Kendala Tersebut}

Cara untuk siswa yang lamban belajar: mengadakan les privat untuk siswa yang mengalami lamban belajar.

Cara untuk kasus bullying: Menyampaikan kepada wali murid bahwa setiap anak ini sama. Selain itu, beberapa guru menenangkan keadaan. Anak anak yg dibully dan membully, duduk dekat guru agar anak tersebut bisa dipantau dengan baik.

\section{UCAPAN TERIMA KASIH}

Terima kasih diberikan kepada dosen pembimbing mata kuliah Pendidikan Inklusi Universitas Muhammadiyah Tangerang. Serta terima kasih penulis ucapkan kepada kepala sekolah, guru, dan peserta didik SDN Kampung
Bulak III Tangerang Selatan atas kerjasamanya dan kesempatan observasi yang telah diberikan kepada penulis.

\section{KESIMPULAN}

Kurikulum yang digunakan di SDN Kampung Bulak III masih menggunakan kurikulum 13 yang berlaku. SDN Kampung Bulak III belum menggunakan kurikulum pendidikan inklusi yang berlaku karena pemerintah belum membuat kebijakan atau mewajibkan sekolah tersebut untuk menggunakan kurikulum pendidikan inklusi. Namun, SD ini tetap menerima anak yang mengalami lamban belajar dan cepat belajar. Seperti yang dipaparkan oleh guru A bahwa selagi siswa tersebut masih mampu untuk diajak berkomunikasi, maka siswa tersebut diterima oleh sekolah ini. Hal ini yang membuat pelaksanaan serta penanganan anak lamban dan cepat belajar di SD ini belum semaksimal pelaksanaan dan penanganan di sekolah yang memang menerapkan kurikulum pendidikan inklusi yang berlaku.

Peneliti berharap dengan adanya penelitian ini, pihak sekolah mampu mempertimbangkan untuk menggunakan kurikulum pendidikan inklusi di SDN Kampung Bulak III agar siswa dengan latar belakang yang berbeda mampu mendapatkan hak bersekolah yang sama seperti siswa lainnya

\section{DAFTAR RUJUKAN}

Budiwibowo, S. (2018). Manajemen Pendidikan . Yogyakarta.

Kemendikbud. (2003, July 08). Sistem Informasi Manajemen Keuangan Kementrian Pendidikan dan Kebudayaan RI. Retrieved from Simkeu Kemendikbud: http://simkeu.kemdikbud.go.id/index.p $\mathrm{hp} /$ peraturan1/8-uu-undang-undang

Mawardi. (2021). Desain Penelitian Tindakan Kelas. Yogyakarta: 2021. 
Moleong, L. (2002). Metodologi Penelitian Kualitatif. Bandung: PT. Remaja Rosdakarya.

Mumpuniarti. (2007). Pendekatan Pembelajaran bagi Anak Hambatan Mental. Yogyakarta: Kanwa Publisher.

Ningsih, R. Y. (2019). STRATEGI PEMBELAJARAN BAGI SISWA SLOW LEARNERS DALAM MENINGKATKAN HASIL BELAJAR SISWA KELAS V DI SDN 158 SELUMA. Bengkulu: IAIN Bengkulu. Retrieved from repository.iainbengkulu.ac.id.

Nurfadhillah, Septy, \& Haryati, Sri. (2021). Pendidikan Inklusif. Tangerang: Pusat Bahasa Universitas Muhammadiyah Tangerang.

Purwaningtyas, M. (2014). STRATEGI PEMBELAJARAN ANAK LAMBAN BELAJAR (SLOW LEARNERS) DI SEKOLAH INKLUSI SD NEGERI GIWANGAN. Yogyakarta: Universitas Negeri Yogyakarta.

Raco. (2010). Metode Penelitian Kualitatif. Jakarta: PT Gramedia Widiasaran.

Setiadi, H. (2016). PELAKSANAAN
PENILAIAN PADA KURIKULUM 2013. Jurnal Penelitian dan Evaluasi Pendidikan, 166-178.

Sinambela, P. N. (2013). KURIKULUM 2013 DAN IMPLEMENTASINYA DALAM PEMBELAJARAN. Generasi Kampus, 17-29.

Suharsimi, A. (1998). Prosedur Penelitian Suatu Pendekatan Praktek. Jakarta: Rineka Cipta.

Supriadi, N., \& Damayanti, R. (2016). Analisis Kemampuan Komunikasi Matematis Siswa Lamban Belajar. AlJabar: Jurnal Pendidikan Matematika, 1-9.

UNIMUS. (2009, Oktober 05). PERATURAN MENTERI PENDIDIKAN NASIONAL REPUBLIK INDONESIA. Retrieved from $\mathrm{pdpt}$ unimus: http://pdpt.unimus.ac.id/2012/wpcontent/uploads/2012/05/Permen-No.70-2009-tentang-pendidiian-inklusifmemiliki-kelainan-kecerdasan.pdf

Wijaya. (2019). Manajemen Pendidikan Inklusif Sekolah Dasar. Jakarta: Kencana. 